\title{
Lateral Enlargement Growth Mechanism of 3C-SiC on Off-Oriented 4H-SiC Substrates
}

\author{
Valdas Jokubavicius, G. Reza Yazdi, Rickard Liljedahl, Ivan Gueorguiev Ivanov, Rositsa \\ Yakimova and Mikael Syväjärvi
}

\section{Linköping University Post Print}

\section{Tweet}

N.B.: When citing this work, cite the original article.

Original Publication:

Valdas Jokubavicius, G. Reza Yazdi, Rickard Liljedahl, Ivan Gueorguiev Ivanov, Rositsa Yakimova and Mikael Syväjärvi, Lateral Enlargement Growth Mechanism of 3C-SiC on OffOriented 4H-SiC Substrates, 2014, Crystal Growth \& Design, (14), 12, 6514-6520.

http://dx.doi.org/10.1021/cg501424e

Copyright: American Chemical Society

http://pubs.acs.org/

Postprint available at: Linköping University Electronic Press

http://urn.kb.se/resolve?urn=urn:nbn:se:liu:diva-112510 


\section{Lateral enlargement growth mechanism of $3 \mathrm{C}-\mathrm{SiC}$ on off- oriented $4 \mathrm{H}-\mathrm{SiC}$ substrates}

Valdas Jokubavicius*, ${ }^{*}$, G. Reza Yazdi ${ }^{1}$, Rickard Liljedahl ${ }^{1}$, Ivan G. Ivanov ${ }^{1}$, Rositsa Yakimova ${ }^{1}$, Mikael

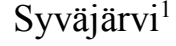

${ }^{1}$ Department of Physics, Chemistry and Biology (IFM), Semiconductor Materials Division, Linköping University, 58183 Linköping, Sweden

ABSTRACT We introduce a 3C-SiC growth concept on off-oriented 4H-SiC substrates using a sublimation epitaxial method. A growth model of $3 \mathrm{C}-\mathrm{SiC}$ layer development via a controlled cubic polytype nucleation on in situ formed on-axis area followed by a lateral enlargement of 3C-SiC domains along the step-flow direction is outlined. Growth process stability and reproducibility of high crystalline quality material are demonstrated in a series of $3 \mathrm{C}-\mathrm{SiC}$ samples with a thickness of about $1 \mathrm{~mm}$. The average values of full width at half-maximum of $\omega$ rocking curves on these samples vary from 34 to 48 arcsec indicating high crystalline quality compared to values found in the literature. The low temperature photoluminescence measurements also confirm a high crystalline quality of $3 \mathrm{C}-\mathrm{SiC}$ and indicate that the residual nitrogen concentration is about $1-2 \times 10^{16} \mathrm{~cm}^{-3}$. Such $3 \mathrm{C}-\mathrm{SiC}$ growth concept may be applied to produce substrates for homoepitaxial $3 \mathrm{C}-\mathrm{SiC}$ growth or seeds which could be explored in bulk growth of 3C-SiC.

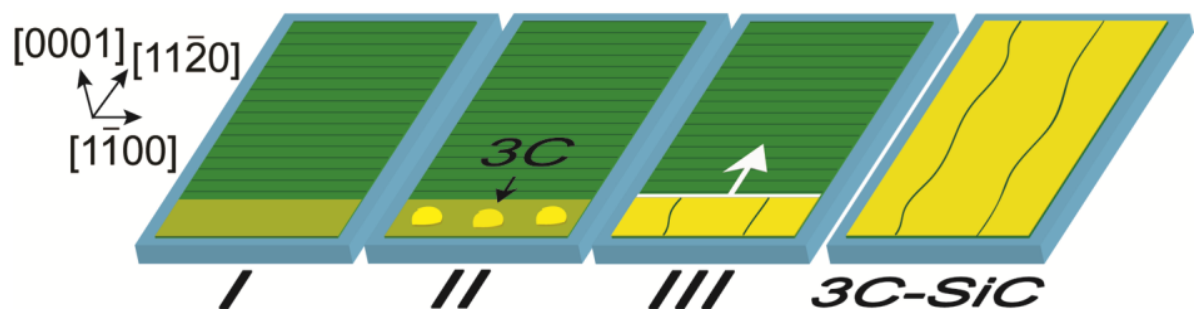

Figure. 3C-SiC formation stages on off-oriented hexagonal $\mathrm{SiC}$ substrates

\footnotetext{
*Valdas Jokubavicius

Department of Physics, Chemistry and Biology (IFM), Semiconductor Materials Division, Linköping University, 58183 Linköping, Sweden

Phone: +4613282641

Email: valjo@ifm.liu.se
} 


\section{INTRODUCTION}

Cubic silicon carbide (3C-SiC) as well as commercially available hexagonal silicon carbide $(4 \mathrm{H}-$ and $6 \mathrm{H}-\mathrm{SiC})$ has excellent thermal, electrical, mechanical and chemical properties. It is very attractive for the development of metal-oxide-semiconductor field-effect transistors for medium power devices, ${ }^{1,2}$ high efficiency solar cells, ${ }^{3,4}$ biocompatible medical devices ${ }^{5}$ or biomarkers. ${ }^{6}$ Furthermore, it is a suitable substrate for the growth of nitride and epitaxial graphene layers. $^{7,8}$

While technologies for producing bulk hexagonal silicon carbide $(\alpha-\mathrm{SiC})$ have significantly advanced and device quality wafers have been commercially available for a number of years, the growth of bulk $3 \mathrm{C}-\mathrm{SiC}$ is still lagging behind its hexagonal counterparts. The main problem hampering the progress in the growth of bulk $3 \mathrm{C}-\mathrm{SiC}$ is a lack of high quality seeds which could be applied in the physical vapor transport (PVT) technique in the same way as it is done for the growth of large $4 \mathrm{H}-$ or $6 \mathrm{H}-\mathrm{SiC}$ crystals. ${ }^{9}$ Moreover, considering thermal stresses created in the seed attached to the lid or graphite plate during the PVT growth, the $3 \mathrm{C}-\mathrm{SiC}$ seed with a thickness close to $1 \mathrm{~mm}$ would be preferable for the growth of low defect density crystals.

The $3 \mathrm{C}-\mathrm{SiC}$ is usually heteroepitaxially grown on the foreign substrates such as silicon or hexagonal $\mathrm{SiC}(\alpha-\mathrm{SiC})$. Large area free-standing 3C-SiC wafers have been produced on silicon. ${ }^{10}$ However, the quality of $3 \mathrm{C}-\mathrm{SiC}$ is limited due to fundamental problems in the $\mathrm{Si} / 3 \mathrm{C}-\mathrm{SiC}$ material system. A high density of structural defects is formed in the grown crystal due to a high mismatch in thermal expansion coefficients and lattice parameters between the silicon and 3CSiC. It was also shown that the defect density in $3 \mathrm{C}-\mathrm{SiC}$ layers grown on silicon tends to saturate in the range between $10^{3}$ and $10^{4} \mathrm{~cm}^{-1} \cdot{ }^{11}$ On the other hand, the $\alpha-\mathrm{SiC}$ is an excellent substrate in terms of lattice parameter, thermal expansion coefficient and chemical compatibility. However, 
the $\alpha-\mathrm{SiC} / 3 \mathrm{C}-\mathrm{SiC}$ system also possesses a fundamental problem related to the formation of structural defects called double positioning boundaries (DPBs). ${ }^{12}$ The DPBs in the $3 \mathrm{C}-\mathrm{SiC}$ can influence electronic properties of the material, interact with impurities and lead to a poor behavior of a large area Schottky contacts. ${ }^{13,14}$ Therefore, the reduction of DPBs density remains one of the primary goals to be achieved in the growth of $3 \mathrm{C}-\mathrm{SiC}$ on $\alpha$-SiC substrates.

The $\alpha$-SiC can be roughly divided into nominally on-axis and off-oriented substrates. Nominally on-axis substrates are commonly used for heteroepitaxial growth of thin 3C-SiC layers via two-dimensional nucleation. ${ }^{15-18}$ In contrast, the off-oriented substrates are the usual choice in homoepitaxial growth of $6 \mathrm{H}$ or $4 \mathrm{H}-\mathrm{SiC}$ layers. The surface of such substrates contains high density of steps. Therefore, incoming atoms are easily incorporated at the step kinks and the homoepitaxial layer grows via a step flow growth mechanism. ${ }^{19}$ However, under certain conditions the growth of $3 \mathrm{C}-\mathrm{SiC}$ on off-oriented $\alpha$-SiC substrates can also be possible. The growth of thin $3 \mathrm{C}-\mathrm{SiC}$ layers directly on off-oriented substrates was demonstrated using the vapor-liquid-solid (VLS) technique. ${ }^{18}$ High quality but restricted area $3 \mathrm{C}-\mathrm{SiC}$ epilayers have been grown using chemical vapor deposition on off-oriented $4 \mathrm{H}-\mathrm{SiC}$ substrates with pre-etched mesas structures. ${ }^{20}$ In contrast, larger size and bulk-like 3C-SiC layers have been demonstrated using sublimation epitaxy techniques on off-oriented $6 \mathrm{H}-\mathrm{SiC}$ substrates. ${ }^{21,}{ }^{22}$ However, such material exhibits low crystalline quality.

The $3 \mathrm{C}-\mathrm{SiC}$ growth concept that is demonstrated in this paper allows a reproducible growth of high crystalline quality thick 3C-SiC layers on off-oriented $4 \mathrm{H}-\mathrm{SiC}$ substrates without foreign polytype inclusions. This concept is demonstrated using a sublimation epitaxial growth method, but the generic concept might probably also be applied to other $\mathrm{SiC}$ growth methods. In the case of $3 \mathrm{C}-\mathrm{SiC}$ growth on conventionally used on-axis substrates, the nucleation of the cubic phase 
occurs in a spontaneous manner over the surface area and is difficult to control. We propose a controllable initial polytype formation and subsequent enlargement of 3C-SiC domains on offoriented substrates leading to a significant reduction in the density of DPBs compared to the 3C$\mathrm{SiC}$ layers grown on nominally on-axis substrates. Moreover, the $3 \mathrm{C}-\mathrm{SiC}$ layers grown via a lateral enlargement mechanism on off-oriented substrates contain large enough DPBs-free areas which can potentially be used as seeds for the bulk $3 \mathrm{C}-\mathrm{SiC}$ growth or can be explored as a substrate for homoepitaxial 3C-SiC growth for various device concepts.

\section{EXPERIMENTAL DETAILS}

The sublimation epitaxial 3C-SiC growth arrangement is depicted in Fig.1 (a). A graphite crucible was heated by RF generator at a frequency of $46 \mathrm{kHz}$. At elevated temperatures a solid $\mathrm{SiC}$ source sublimes and vapor species (mainly $\mathrm{Si}, \mathrm{Si}_{2} \mathrm{C}$ and $\mathrm{SiC}_{2}$ ) are transferred to the substrate where they condense and form $\mathrm{SiC}$ crystal. The driving force for such transfer is a temperature gradient between the source and the substrate. It has been shown that this type of sublimation epitaxial configuration may reach a very high growth rate (up to $2 \mathrm{~mm} / \mathrm{h}$ at temperatures up to $\left.2000^{\circ} \mathrm{C}\right){ }^{23}$
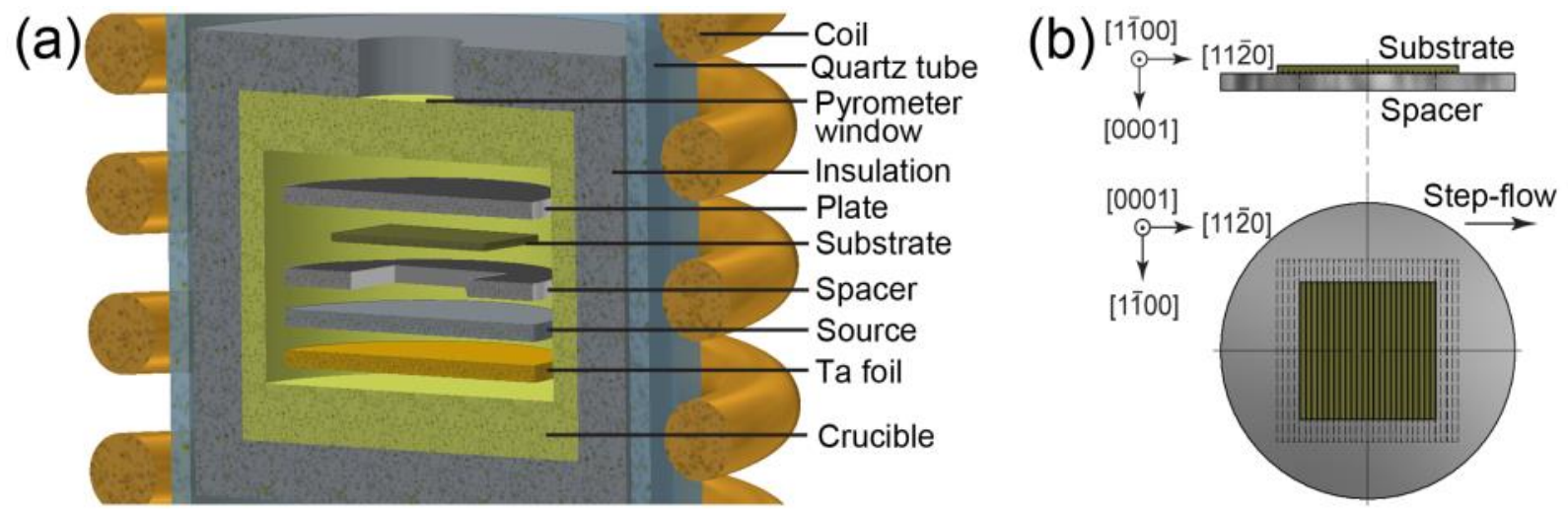

Figure 1. (a) Sublimation epitaxial growth arrangement. (b) Positioning of the substrate on top of the spacer. 
A graphite spacer with thickness of $1 \mathrm{~mm}$ was placed between the source and the substrates. In all experiments a square opening of $7 \times 7 \mathrm{~mm}^{2}$ in the spacer was used. All substrates were chemomechanically polished $4 \mathrm{H}-\mathrm{SiC}$ having 4 deg off-orientation from (0001) toward $<11-20>$ direction cut in rectangular pieces of $10 \times 10 \mathrm{~mm}^{2}$ with one of the substrate sides aligned perpendicularly to the step-flow direction. In the growth cell the substrate was placed on top of the spacer in a way that the sides of the square shaped spacer opening and the sides of the rectangular substrate were aligned to each other as shown in Fig.1 (b). Such positioning of the substrate and the spacer is a crucial element for the subsequent in-situ formation of a large terrace at the substrate edge with an on-axis surface on which the initial 3C-SiC domains are formed before their enlargement along the step-flow direction.

Polycrystalline $\mathrm{SiC}$ plates were used as a source material. In addition, a tantalum (Ta) foil was inserted under the source. It acts as a carbon getter at elevated temperatures, and the growth proceeds in a silicon enriched environment which is preferable for the formation of the $3 \mathrm{C}-\mathrm{SiC}{ }^{24}$ A graphite plate was placed on the top of the substrate in order to prevent backside sublimation of the substrate. The temperature was measured on the top of the crucible via the opening in the insulation material using an infrared pyrometer.

Before the growth all substrates were chemically cleaned with acetone and ethanol followed by $\mathrm{H}_{2} \mathrm{O}: \mathrm{NH}_{3}: \mathrm{H}_{2} \mathrm{O}_{2}(5: 1: 1)$ and $\mathrm{H}_{2} \mathrm{O}: \mathrm{HCl}: \mathrm{H}_{2} \mathrm{O}_{2}(6: 1: 1)$. Growth times up to $2 \mathrm{~h}$ were explored, and the growth temperature was varied from 1650 to $1900^{\circ} \mathrm{C}$. All experiments were performed in vacuum $\left(10^{-5}\right.$ mbar). The surface of the samples was characterized using an optical microscope with Nomarski interference contrast and an atomic force microscope (AFM). The crystalline quality was evaluated by high resolution X-ray diffraction (HRXRD) using Philips X'Pert 
HRXRD diffractometer operating in a triple axis mode with $\mathrm{Cu} \mathrm{K} \alpha 1$ anode. In addition, low temperature photoluminescence (LTPL) measurements at a temperature of $2 \mathrm{~K}$ with the samples immersed in pumped liquid helium, using as an excitation the $351 \mathrm{~nm}$ line of an Ar-ion laser (about $2-3 \mathrm{~mW}$ focused to a spot of diameter $\sim 100 \mu \mathrm{m}$ on the sample) were performed. The luminescence was dispersed by a monochromator (Jobin-Yvon HR 460) coupled to a CCD camera. The spectral resolution of the PL system is approximately $1 \AA$.

\section{RESULTS AND DISCUSSIONS}

In order to evaluate the reproducibility of results, a series of five 3C-SiC samples was grown on off-oriented $4 \mathrm{H}-\mathrm{SiC}$ substrates using similar growth conditions (growth rate $\sim 0,5 \mathrm{~mm} / \mathrm{h}$, growth temperature $-1900{ }^{\circ} \mathrm{C}$, growth time $-2 \mathrm{~h}$ ). A typical 3C-SiC layer obtained under the conditions mentioned above is shown in Fig. 2 (a). The thickness of the layer is about $1.0 \mathrm{~mm}$. Such a thickness is required to completely cover the $7 \times 7 \mathrm{~mm}^{2}$ surface with $3 \mathrm{C}$-SiC via the lateral enlargement mechanism. A 100\% surface coverage with the cubic polytype was confirmed in all samples using LTPL. The lateral enlargement growth mechanism can extend the domains several millimeters all the way from the edge, where they nucleate, to the opposite side of the sample. This leads to the formation of 3C-SiC layer which contains a few DPBs which propagate via the entire length of the surface along the step-flow direction (Fig. 2 (a) enlarged view). Usually single domains of up to $2 \times 7 \mathrm{~mm}^{2}$ are obtained when growing on a $7 \times 7 \mathrm{~mm}^{2}$ surface area. For comparison, we performed growth of $3 \mathrm{C}-\mathrm{SiC}$ on a chemomechanically polished nominally onaxis $4 \mathrm{H}-\mathrm{SiC}$ (0001) substrate using the same growth arrangement and the same growth conditions as for the sample shown in Fig. 2 (a). As seen in Fig. (b), the 3C-SiC layer on nominally on-axis substrate exhibit mosaic structure with high density of DPBs. A typical 
domain size is less than $1 \mathrm{~mm}^{2}$, which coincides with the results reported on the growth of 3C$\mathrm{SiC}$ on nominally on-axis hexagonal $\mathrm{SiC}$ substrates using sublimation epitaxial growth. ${ }^{25}$
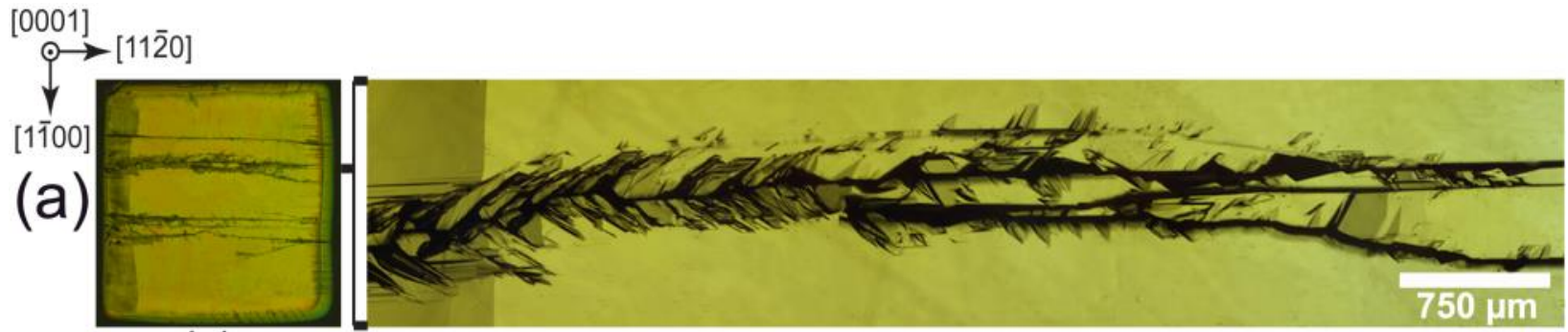

4 deg.

(b)
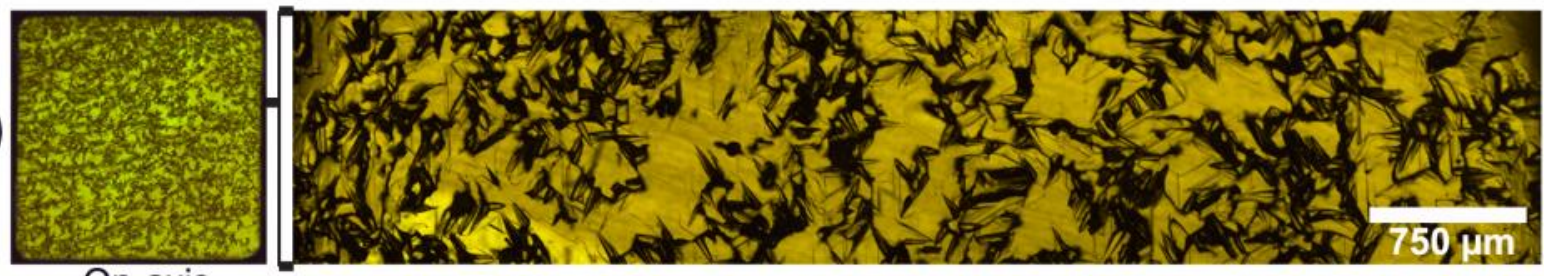

On-axis

Figure 2. Optical micrographs of $1 \mathrm{~mm}$ thick $3 \mathrm{C}-\mathrm{SiC}$ samples grown on $4 \mathrm{H}-\mathrm{SiC}(0001)$ substrates: (a) 4 degrees off-oriented, (b) nominally on-axis. The left side of the picture shows an overview of the $3 \mathrm{C}-\mathrm{SiC}$ sample with a surface area of $7 \times 7 \mathrm{~mm}^{2}$ and the right side is an enlarged view demonstrating propagation of double positioning boundaries.

The HRXRD $\omega$ rocking curves were measured on seven different points distributed over each sample using (111) Bragg reflection and a footprint of $1 \times 2.7 \mathrm{~mm}^{2}$. The values of the full width at half maximum (FWHM) of $\omega$ rocking curves on the five $3 \mathrm{C}$-SiC samples grown at the same growth conditions vary from 26 to 56 arcseconds (Fig. 3 (a)) with the average value in each sample being 39, 36, 48, 34, 35 arcsec. For a comparison, a mapping of FWHM of $\omega$ rocking curves was done using the same footprint on a 3 in. commercial 3C-SiC (001) substrate which was grown on undulant silicon wafer and 4 deg off-oriented $4 \mathrm{H}-\mathrm{SiC}$ substrate used in this study. 
The (002) and (111) Bragg reflections were used for the commercial 3C-SiC and 4 deg substrates, respectively. The average value from 22 measurement points of $105 \operatorname{arcsec}$ was obtained on the commercial $3 \mathrm{C}-\mathrm{SiC}$ substrate. In comparison, the measurement on the $4 \mathrm{H}-\mathrm{SiC}$ substrate shows an average value of only 9 arcsec from seven measurement points. These results together with FWHM values of $\omega$ rocking curves in various $3 \mathrm{C}$-SiC samples available from the literature are presented in Fig. 3 (b).
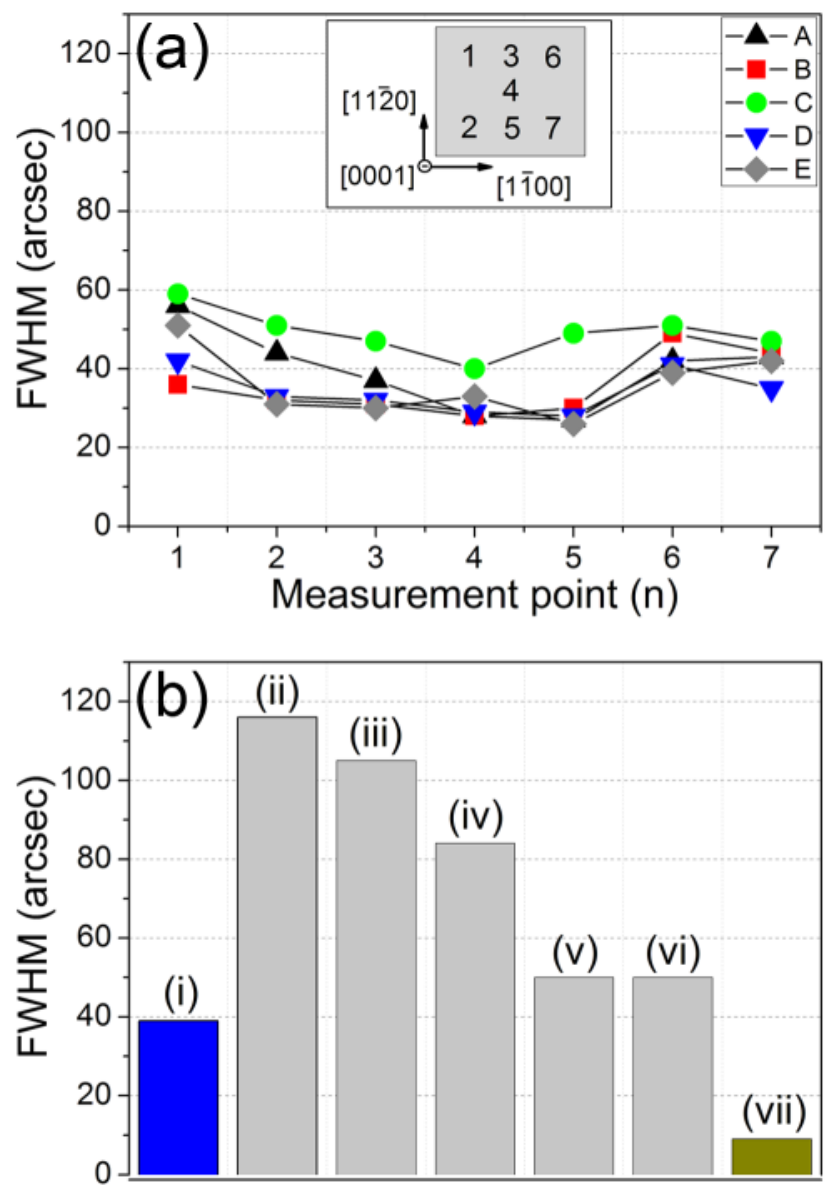

Figure 3. (a) FWHM values on five $3 \mathrm{C}-\mathrm{SiC}$ samples grown in this study. The inset indicates measurement point position. (b) FWHM values of: (i) - five samples in this study (average value), (ii) - homoepitaxial 3C-SiC (111), ${ }^{26}$ (iii) - 3 in. 3C-SiC(001), (iv) - homoepitaxial 3C- 
$\mathrm{SiC}(001),{ }^{27}(\mathrm{v})$ - heteroepitaxial 3C-SiC $(111),{ }^{26}$ (vi) - heteroepitaxial 3C-SiC (111), ${ }^{17}$ (vii) - 4 deg off-oriented 4H-SiC.

In order to complement the HRXRD data, we performed LTPL measurements at $2 \mathrm{~K}$ on the same five samples. The LTPL spectrum shown in Fig. 4 is representative for all samples. It was measured in the center of the sample where the thickness of the 3C-SiC layer is about $490 \mu \mathrm{m}$. It exhibits sharp and well resolved near-band-edge features, namely, the nitrogen-bound-exciton no-phonon line or zero-phonon line (ZPL) with its four phonon replicas (TA, LA, TO and LO) as well as lines associated with multiple bound-exciton complexes with up to four electron-hole pairs (denoted as $\left.\alpha_{2-4}\right)$ which indicate high quality $3 \mathrm{C}-\mathrm{SiC}$ material. ${ }^{28-30}$

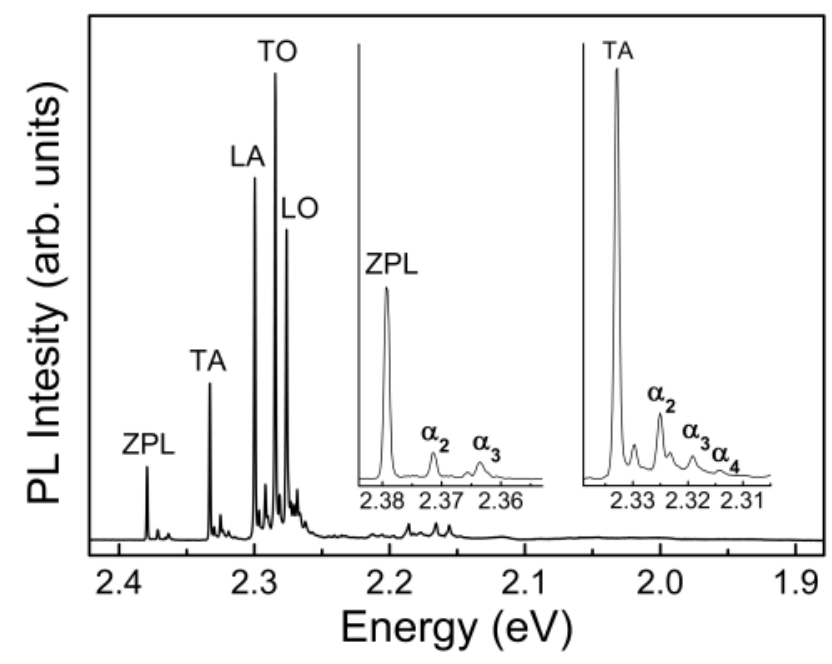

Figure 4. LTPL spectrum of 3C-SiC. The insets expand the regions near the ZPL and its TA phonon replica, showing the presence of multiple bound-exciton complexes.

The intensity ratios of ZPL, TA, LA with respect to the TO line can provide information on the biaxial stress in the $3 \mathrm{C}-\mathrm{SiC}$ crystal. ${ }^{31}$ The LA is the line most sensitive to biaxial stress followed 
by LO, TA and TO which is almost unaffected by biaxial stress. ${ }^{31}$ Therefore, the intensity ratio between the LA and TO is informative biaxial stress indicator. The variations in intensity ratios of ZPL, TA, LA with respect to TO in five $3 \mathrm{C}-\mathrm{SiC}$ samples grown using lateral enlargement mechanism and comparison of such intensity ratios available from the literature is presented in Table 1. The ratio between $\mathrm{I}_{\mathrm{LA}} / \mathrm{I}_{\mathrm{TO}}$ varies in a range of $0.74-0.80$ which is indicating a low biaxial stress in 3C-SiC grown in this study.

We have not observed free-exciton related emissions due to the presence of residual nitrogen. The concentration of nitrogen doping can be estimated in the range of $1-2 \times 10^{16} \mathrm{~cm}^{-3}$ using the FWHM of TA-phonon replica, as proposed in reference. ${ }^{32}$

Table 1. Intensity ratios of characteristic $3 \mathrm{C}-\mathrm{SiC}$ peaks in different samples.

\begin{tabular}{|l|l|l|l|l|l|l|}
\hline \multirow{4}{*}{$\begin{array}{l}\text { This } \\
\text { study }\end{array}$} & Sample & $\mathrm{I}_{\mathrm{ZP}} / \mathrm{I}_{\mathrm{TO}}$ & $\mathrm{I}_{\mathrm{TA}} / \mathrm{I}_{\mathrm{TO}}$ & $\mathrm{I}_{\mathrm{LA}} / \mathrm{I}_{\mathrm{TO}}$ & $\mathrm{I}_{\mathrm{LO}} / \mathrm{I}_{\mathrm{TO}}$ & Thickness \\
\cline { 2 - 7 } & $\mathrm{A}$ & 0.17 & 0.34 & 0.75 & 0.70 & $\sim 490 \mu \mathrm{m}$ \\
\cline { 2 - 7 } & $\mathrm{B}$ & 0.11 & 0.28 & 0.78 & 0.61 & $\sim 490 \mu \mathrm{m}$ \\
\cline { 2 - 7 } & $\mathrm{C}$ & 0.12 & 0.29 & 0.74 & 0.61 & $\sim 490 \mu \mathrm{m}$ \\
\cline { 2 - 7 } & $\mathrm{D}$ & 0.11 & 0.27 & 0.77 & 0.58 & $\sim 490 \mu \mathrm{m}$ \\
\cline { 2 - 7 } & $\mathrm{E}$ & 0.09 & 0.25 & 0.80 & 0.53 & $\sim 490 \mu \mathrm{m}$ \\
\hline \multirow{3}{*}{$\begin{array}{l}\text { Available } \\
\text { in }\end{array}$} & $3 \mathrm{C}-\mathrm{SiC} / \mathrm{Si}^{31}$ (stressed) & 0.02 & 0.16 & 0.19 & 0.3 & $10.4 \mu \mathrm{m}$ \\
\cline { 2 - 7 } & $3 \mathrm{C}-\mathrm{SiC} / 4 \mathrm{H}-\mathrm{SiC}^{16}$ & 0.2 & 0.41 & 0.67 & 0.73 & $4 \mu \mathrm{m}$ \\
\cline { 2 - 7 } & $3 \mathrm{C}-\mathrm{SiC} / \mathrm{Si}^{31}$ (free film) & 0.14 & 0.33 & 0.73 & 0.73 & $15 \mu \mathrm{m}$ \\
\cline { 2 - 7 } & $3 \mathrm{C}-\mathrm{SiC} / 6 \mathrm{H}-\mathrm{SiC}^{17}$ & 0.59 & 0.67 & 1 & 0.67 & $760 \mu \mathrm{m}$ \\
\hline
\end{tabular}

The HRXRD and LTPL results indicate that the lateral enlargement mechanism allows reproducible growth of $3 \mathrm{C}-\mathrm{SiC}$ layers that exhibit high crystalline quality.

\section{GROWTH MODEL}

The formation of $3 \mathrm{C}-\mathrm{SiC}$ on off-oriented $4 \mathrm{H}-\mathrm{SiC}$ can be divided into three interconnected stages (Fig. 5): I) formation of a large terrace (LT) at the edge of 4H-SiC homoepitaxial layer 
(HL), II) formation of the 3C-SiC domains, III) merging and lateral enlargement of the 3C-SiC domains along the step-flow direction. The model is generic and the thickness needed for full 3C-SiC conversion depends on the degree of off-orientation and substrate length in the [11-20] direction. In order to analyze each stage presented in Fig. 5, different sets of experiments were performed. For the analysis of Stage I and partly of Stage II, we have investigated an initial homoepitaxial growth of $4 \mathrm{H}-\mathrm{SiC}$ which occurred during the temperature ramp-up $\left(20^{\circ} \mathrm{C} / \mathrm{min}\right)$ to $1650^{\circ} \mathrm{C}, 1700^{\circ} \mathrm{C}, 1750^{\circ} \mathrm{C}, 1800^{\circ} \mathrm{C}$ and $1825^{\circ} \mathrm{C}$. After the targeted temperature was reached, the graphite crucible was immediately cooled down to room temperature with the cool-down rate of $20{ }^{\circ} \mathrm{C} / \mathrm{min}$. By analyzing homoepitaxial layers formed at different temperatures, we have revealed morphological changes in the HL which have provided information needed to explain the mechanism of the LT formation. For the analysis of Stage II and III, the 3C-SiC layers were grown at $1900^{\circ} \mathrm{C}$ using growth time up to $2 \mathrm{~h}$ in order to investigate initial formation and lateral enlargement of the $3 \mathrm{C}-\mathrm{SiC}$ domains.

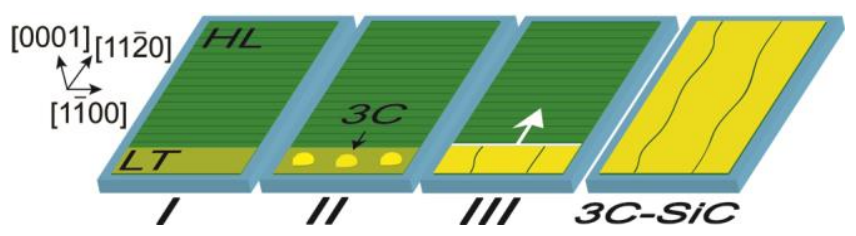

Figure 5. : 3C-SiC formation stages on off-oriented hexagonal $\mathrm{SiC}$ substrate.

Stage I: Formation of a large terrace (LT) at the edge of $4 \mathrm{H}$-SiC homoepitaxial layer (HL). The area of HL is determined by the opening in the spacer and in these experiments it was $7 \times 7$ $\mathrm{mm}^{2}$. Considering that the HL has a rectangular shape given by the square spacer opening, the LT that evolves into an on-axis surface is always formed along the edge of the rectangular HL area which is aligned perpendicularly to the step-flow direction as shown in Fig 6 (a-b). Optical 
micrographs in Fig. 6 (c-g) show a fragment of the HL edge where the formation of the LT occurs. A dashed line in Fig. 6 (c-g) indicates a border between the substrate area that is covered by the spacer, schematically illustrated in the enlarged area of Fig. 6 (b), and the area which was exposed to vapor species sublimed from the source.

The initial homoepitaxial growth is seen in the extract of Fig. 6 (c) which shows that at $1650^{\circ} \mathrm{C}$ there is no clear indication of any morphological disturbances that could be cubic polytype inclusions within the layer. At $1700^{\circ} \mathrm{C}$ the steps at the border, indicated with a dashed line, become curved (extract of Fig. 6 (d)). Meanwhile, the rest of the HL surface contains straight steps. As the HL continues to grow, the surface at the border starts to undergo morphological changes. At $1750^{\circ} \mathrm{C}$ a clear separation of the HL steps and the steps in the area covered by the spacer can be observed (extract of Fig. 6 (e)). As demonstrated in Fig. 6 (b), steps at the edge, where the LT forms, have no follow-up steps which could result in a continuous feeding of steps along the step-flow direction from the area covered by the spacer. The supply of vapor species (depicted as "Flux" in the enlarged area of Fig 6(b)) which could be used to create follow-up steps is blocked by the spacer. The difference in steps propagation velocities at the border marked in dashed line in Fig. 6 (c-g) induces a brake or disorder in a continuous step train structure along the edge of the HL. Consequently, the LT starts to develop. At $1800^{\circ} \mathrm{C}$ the LT evolves into a flat/on-axis surface that is growing in a spiral mode as confirmed by the AFM in the extract of Fig. 6(f). 

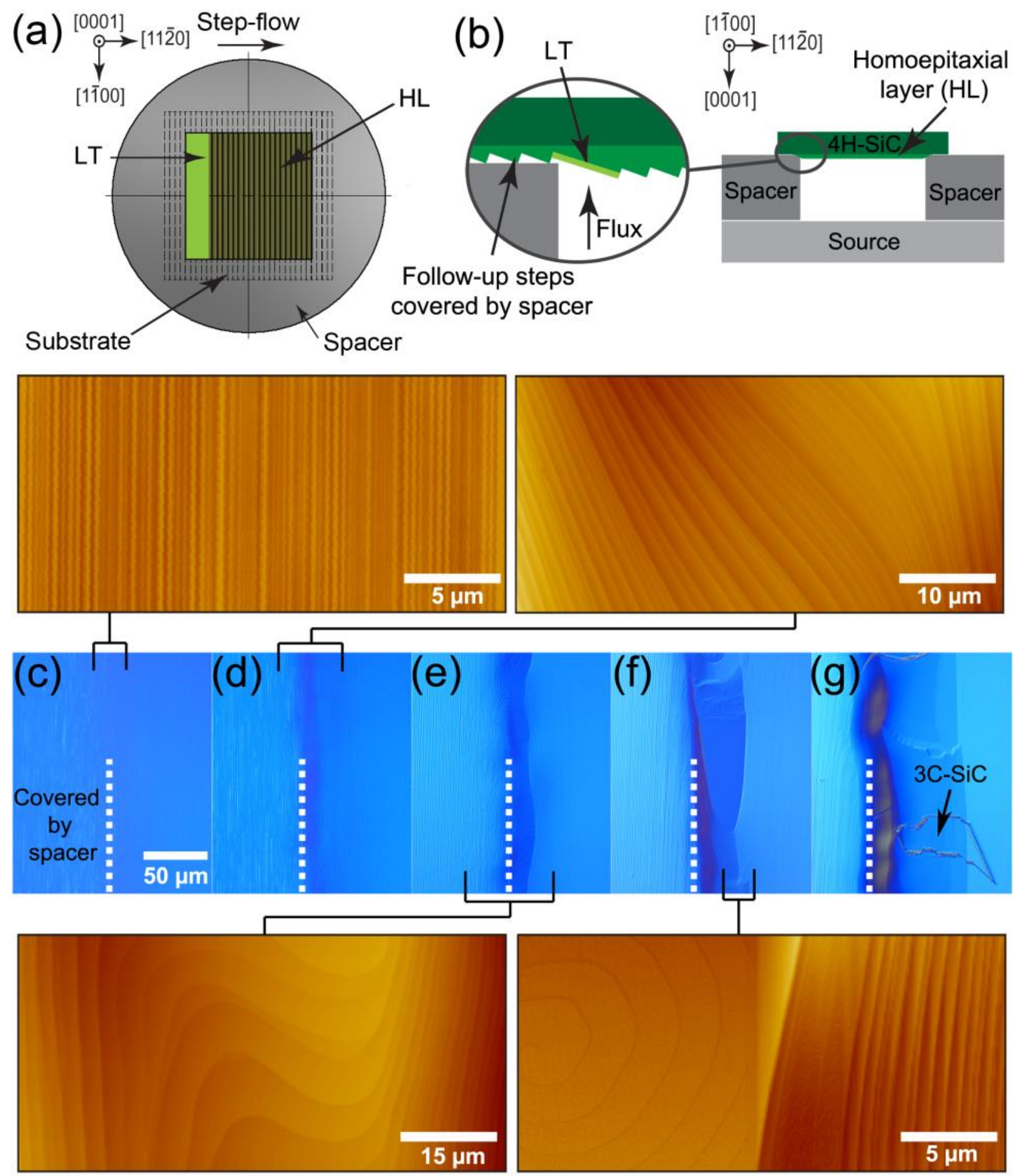

Figure 6. Schematic illustration of the LT position (a-b) and optical micrographs showing evolution of the LT at the edge of the HL grown during temperature ramp up to (c) $1650^{\circ} \mathrm{C}$, (d) 
$1700^{\circ} \mathrm{C}$, (e) $1750{ }^{\circ} \mathrm{C}$, (f) $1800^{\circ} \mathrm{C}$ and $(\mathrm{g}) 1825^{\circ} \mathrm{C}$ respectively. The enlarged areas are AFM pictures.

Stage II: Formation of $3 \mathrm{C}-\mathrm{SiC}$ domains. While the LT is still developing the 3C-SiC domains, observable with an optical microscope, start to form preferentially on the LT as seen in the sample grown at $1825^{\circ} \mathrm{C}$, (Fig. $6(\mathrm{~g})$ ). Based on the surface analysis by AFM the LT surface at this stage is covered with spirals having terraces the width of which vary from $800 \mathrm{~nm}$ up to 1.8 $\mu \mathrm{m}$. In contrast, the width of step terraces in the central part of the HL, where the growth proceeds via step-flow mode, is only up to $200 \mathrm{~nm}$ and no 3C-SiC domains can be observed. The prioritized formation of $3 \mathrm{C}-\mathrm{SiC}$ on the $\mathrm{LT}$ follows the nucleation theory involving relationship between the terrace width and growth conditions, in particular, supersaturation [18]. Under the same growth conditions, the $3 \mathrm{C}-\mathrm{SiC}$ is preferably formed on wider step terraces since the critical supersaturation level needed to form $2 \mathrm{D}$ nuclei of $3 \mathrm{C}-\mathrm{SiC}$ is easier exceeded on wider terraces compared to the narrower ones. This explains why the initial formation of 3C-SiC domains is concentrated on the LT.

Stage III: Merging and lateral enlargement of 3C-SiC domains along step-flow direction. The 3C-SiC domains formed during Stage II merge together and cover the entire LT surface while the rest of the sample surface remains covered with $4 \mathrm{H}-\mathrm{SiC}$ growing via step-flow growth mechanism. In such way, a 3C-SiC growth front which enlarges along the step-flow growth direction is created (Fig. 7). The crystalline quality of this front significantly influences the quality of the final 3C-SiC layer. The DPBs formed on the LT propagate along the step-flow direction together with the $3 \mathrm{C}-\mathrm{SiC}$ growth front. If additional/parasitic $3 \mathrm{C}-\mathrm{SiC}$ domains are not present on the HL, the growth front will propagate along the step-flow direction until it reaches 
the opposite edge of the HL and completely covers the surface with 3C-SiC. In contrast, if the growth front collides with the parasitic 3C-SiC domains (Fig. 7 (b, d)) on the HL, it may lead to the formation of new DPBs that can cascade into further growth disturbances.

Usually, the formation of parasitic 3C-SiC domains are caused by structural defects which originate from the substrate and propagate all the way up to the surface of the HL. In addition, they could be induced by mechanical polishing scratches, presence of solid particles on the surface or various polycrystalline inclusions formed during the growth. These defects act as obstacles for the continuous flow of steps and can induce formation of parasitic 3C-SiC domains in the central part of the HL as well. Therefore, the quality of the substrate surface has to be well considered in order to obtain 3C-SiC layer with low density of structural defects.

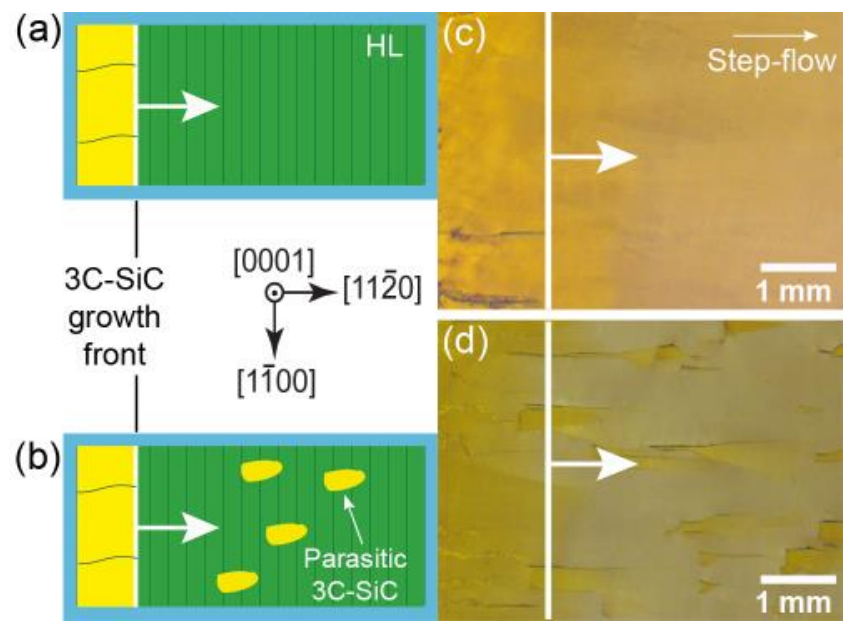

Figure 7. Schematic drawings and optical micrographs showing propagation of the $3 \mathrm{C}-\mathrm{SiC}$ growth front (white lines in all images) without ((a) and (c)) and with ((b) and (d)) parasitic 3CSiC inclusions on the HL. 
In order to further understand the $3 \mathrm{C}-\mathrm{SiC}$ enlargement mechanism, a cross-sectional analysis was made on a sample with incomplete surface coverage with 3C-SiC (Fig. 8). After the formation of the $3 \mathrm{C}-\mathrm{SiC}$ growth front it starts to enlarge laterally along the step-flow direction. At the same time, a transition layer starts to form and propagate between the homoepitaxial $4 \mathrm{H}-$ $\mathrm{SiC}$ and laterally enlarging 3C-SiC layer. This occurs at a layer thickness of about 20-30 $\mu \mathrm{m}$.

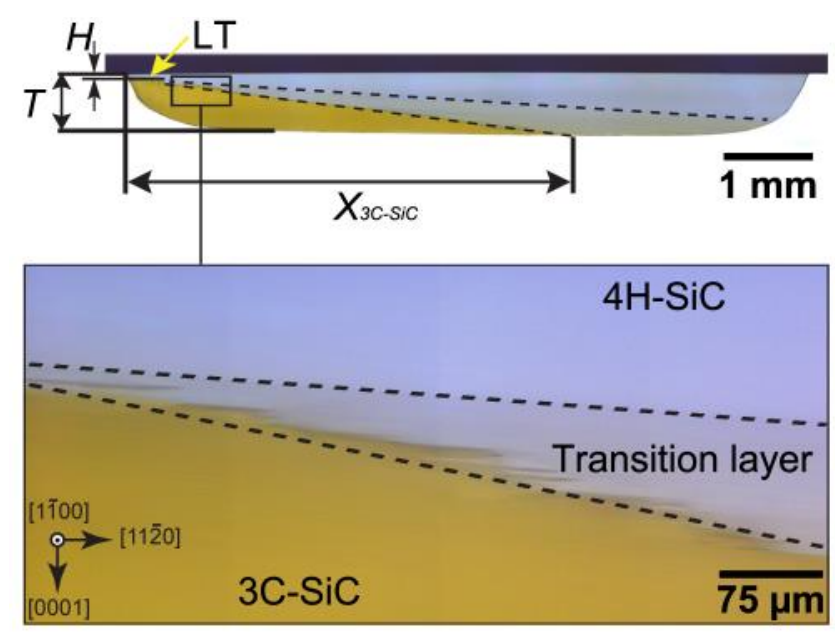

Figure 8. Optical micrograph of the cross sectional view of the sample with the thickness of about $650 \mu \mathrm{m}$ and incomplete surface coverage with 3C-SiC.

The approximate enlargement distance of the transition layer $\left(X_{\text {tran }}\right)$ (Fig. 8$)$ is proportional to the total thickness of the grown layer and inversely proportional to the tangent of the off-cut angle. Meanwhile, the approximate enlargement distance of $3 \mathrm{C}-\mathrm{SiC}\left(X_{3 C-S i C}\right)$ is inversely proportional to the tangent of double off-cut angle as shown in equations below:

$$
X_{\text {tran }} \sim \frac{(T-H)}{\tan \alpha}, X_{3 C-S i C} \sim \frac{(T-H)}{\tan 2 \alpha},
$$

where $T$ - total thickness of grown layer, $H$ - thickness at which LT is formed $(20-30 \mu \mathrm{m})$ and $\alpha$ - the off-cut angle. 
The transition layer could originate due to a very small mismatch in a lattice parameter between the $3 \mathrm{C}-\mathrm{SiC}$ and the hexagonal $\mathrm{SiC}$ substrate. A previous study of $3 \mathrm{C}-\mathrm{SiC}$ grown on nominally on-axis hexagonal $\mathrm{SiC}$ substrates using sublimation epitaxy also revealed the existence of thin transition layer in which polytypic transformation occurred through admixture of $15 \mathrm{R}-, 6 \mathrm{H}-$ and $3 \mathrm{C}-\mathrm{SiC}$ and other irregular stacking sequences. ${ }^{33}$ The advantage of the $3 \mathrm{C}-\mathrm{SiC}$ growth on nominally on-axis substrates is that the transition layer is localized at the interface between the $3 \mathrm{C}-\mathrm{SiC}$ and the substrate, and does not propagate to the growing surface. In contrast, when using off-oriented substrates the transition layer propagates to the surface and stays there until it is completely covered with $3 \mathrm{C}$-SiC domains that are enlarging along the step-flow direction.

\section{CONCLUSIONS}

A series of $3 \mathrm{C}-\mathrm{SiC}$ samples were grown using the same growth conditions on off-oriented $4 \mathrm{H}-$ SiC substrates. We have demonstrated a reproducible and well controllable growth process which allows to obtain high crystalline quality 3C-SiC samples without foreign polytype inclusions on a surface area of $7 \times 7 \mathrm{~mm}^{2}$ and the total layer thickness of $1 \mathrm{~mm}$. Single domains of up to $2 \times 7 \mathrm{~mm}^{2}$ are usually present on such size surfaces. The growth of $3 \mathrm{C}$-SiC layers overpasses several interconnected stages. The 3C-SiC domains initially nucleate on an in-situ formed large terrace with on-axis surface and subsequently laterally enlarges along the step-flow direction until a complete surface coverage with $3 \mathrm{C}-\mathrm{SiC}$ is obtained. In such way, a significant reduction of DPBs compared to the cubic polytype growth using the on-axis substrates is achieved. The surface area covered by $3 \mathrm{C}-\mathrm{SiC}$ depends on the geometrical constrains, mainly on the size of the opening in the spacer and the total thickness of the layer, since an approximate 
enlargement distance of $3 \mathrm{C}-\mathrm{SiC}$ is inversely proportional to the tangent of double off-cut angle. Therefore, this growth mechanism is generic and could be used to grow 3C-SiC layers on $4 \mathrm{H}-$ $\mathrm{SiC}$ substrates having other off-cut angles and larger substrate surfaces. This would allow one to produce even larger DPBs-free areas. The resulting 3C-SiC layers could be used as seeding layers for the bulk or homoepitaxial growth.

\section{AUTHOR INFORMATION}

\section{Corresponding Author}

*valjo@ifm.liu.se

\section{Funding Sources}

The Swedish Energy Agency and the Swedish Governmental Agency for Innovation Systems (Vinnova)

\section{REFERENCES}

[1] Ohshima, T.; Lee, K. K.; Ishida, Y.; Kojima, K.; Tanaka, Y.; Takahashi, T.; Yoshikawa, M.; Okumura, H.; Arai, K.; Kamiya, T. Jpn. J. Appl. Phys. 2003, 42, L625.

[2] Schöner, A.; Krieger, M.; Pensl, G.; Abe, M.; Nagasawa, H. Chem. Vap. Deposition 2006, $12,523-530$.

[3] Beaucarne, G.; Brown, A. S.; Keevers, M. J.; Corkish, R.; Green, M. A. Prog Photovoltaics Res Appl 2002, 10, 345-353. 
[4] Richards, B. S.; Lambertz, A.; Corkish, R. P.; Zorman, C. A.; Mehregany, M.; Ionescu, M.; Green, M. A. Proceedings of 3rd World Conference on Photovoltaic Energy Conversion 2003, 3, 2738.

[5] Saddow, S. E.; Frewin, C. L.; Coletti, C.; Schettini, N.; Weeber, E.; Oliveros, A.; Jarosezski, M. Mater. Sci. Forum 2011, 679 - 680, 824.

[6] Beke, D.; Szekrényes, Z.; Balogh, I.; Czigány, Z.; Kamarás, K.; Gali, A. J. Mat. Res. 2013, 28,44 .

[7] Masri, P.; Rouhani Laridjani, M.; Breton, O.; Averous, M. Mater. Sci. Eng. B 2001, 82, 5355.

[8] Yazdi, G. R.; Vasiliauskas, R.; Iakimov, T.; Zakharov, A.; Syväjärvi, M.; Yakimova, R. Carbon 2013, 57, 477-484.

[9] Tairov, Y. M.; Tsvetkov, V. F. J. Cryst. Growth 1978, 43, 209-212.

[10] Nagasawa, H.; Kawahara, T.; Yagi, K. Mat. Sci. Forum 2002, 389, 319.

[11] Severino, A.; Ruggero, A.; Camarda, M.; Piluso, N.; La Via, F. Materials Science Forum 2012, 711, 27.

[12] Kong, H. S.; Glass, J. T.; Davis, R. F. J. Mater. Res. 1989, 4, 204-214.

[13] Eriksson, J.; Weng, M. H.; Roccaforte, F.; Giannazzo, F.; Leone, S.; Raineri, V. Appl. Phys. Lett. 2009, 95, 081907. 
[14] Kohyama, M.; Yamamoto, R. Solid State Phenom. 1994, 37, 55.

[15] Vasiliauskas, R.; Marinova, M.; Hens, P.; Wellmann, P.; Syväjärvi, M.; Yakimova, R. Cryst. Growth Des. 2012, 12, 197.

[16] Li, X.; Jacobson, H.; Boulle, A.; Chaussende, D.; Henry, A. ECS J. Solid State Sci. Technol. 2014, 3, P75-P81.

[17] Sun, J. W.; Ivanov, I. G.; Liljedahl, R.; Yakimova, R.; Syväjärvi, M. Appl. Phys. Lett. 2012, $100,252101$.

[18] Soueidan, M.; Ferro, G.; Kim-Hak, O.; Cauwet, F.; Nsouli, B. Cryst. Growth Des. 2008,8, 1044.

[19] Kimoto, T.; Matsunami, H. J. Appl. Phys. 1994, 75, 850-859.

[20] Powell, J. A.; Neudeck, P. G.; Trunek, A. J.; Beheim, G. M.; Matus, L. G.; Hoffman, R. W.; Keys, L. J. Appl. Phys. Lett. 2000, 77, 1449-1451.

[21] Furusho, T.; Sasaki, M.; Ohshima, S.; Nishino, S. J. Cryst. Growth 2003, 249, $216-221$.

[22] Syväjärvi, M.; Yakimova, R.; Jacobsson, H.; Janzén, E. Mater. Sci. Forum 2001, 353, 143.

[23] Syväjärvi, M.; Yakimova, R.; Tuominen, M.; Kakanakova-Georgieva, A.; MacMillan, M.

F.; Henry, A.; Wahab, Q.; Janzén, E. J. Cryst. Growth 1999, 197, 155-162.

[24] Vodakov, Y. A.; Roenkov, A. D.; Ramm, M. G.; Mokhov, E. N.; Makarov, Y. N. Phys. Status Solidi B 1997, 202, 177-200. 
[25] Yakimova, R.; Yazdi, G. R.; Sritirawisarn, N.; Syväjärvi, M. Mater. Sci. Forum 2006, 527$529,283-286$.

[26] Vasiliauskas, R.; Marinova, M.; Syväjärvi, M.; Liljedahl, R.; Zoulis, G.; Lorenzzi, J.; Ferro, G.; Juillaguet, S.; Camassel, J.; Polychroniadis, E. K.; Yakimova, R. J. Cryst. Growth 2011, 324, $7-14$.

[27] Hens, P.; Müller, J.; Wagner, G.; Liljedahl, R.; Yakimova, R.; Spiecker, E.; Wellmann, P.; Syväjärvi, M. Mater. Sci. Forum 2012, 717-720, 177-180.

[28] Bergman, J. P.; Janzén, E.; Choyke, W. J. Phys. Status Solidi B 1998, 210, 407-413.

[29] Choyke, W. J.; Hamilton, D. R.; Patrick, L. Phys.Rev. 1964, 133, A1163-A1166.

[30] Latu-Romain, L.; Chaussende, D.; Balloud, C.; Juillaguet, S.; Rapenne, L.; Pernot, E.; Camassel, J.; Pons, M.; Madar, M. Mater. Sci. Forum 2006, 527, 99.

[31] Choyke, W. J.; Feng, Z. C.; Powell, J. A. J. Appl. Phys. 1988, 64, 3163-3175.

[32] Camassel, J.; Juillaguet, S.; Zielinski, M.; Balloud, C. Chemical Vapor Deposition 2006, 12 , $549-556$.

[33] Marinova, M.; Mantzari, A.; Polychroniadis, E. K. Solid State Phenomena 2010, 159, 39. 